\title{
CONSEILS AUX VOYAGERS: REFLEXÕES SO- BRE A UTILIZAÇÃO DA COMUNICAÇÃO DI- GITAL NO PROCESSO DE CONSTRUÇÃO DO IMAGINÁRIO TURÍSTICO DE ESTRANGEIROS NO BRASIL
}

\author{
GRAZIELLE BETINA BRANDT \\ UNIVERSITÉ DU QUEBÉC À RIMOUSKI \\ CANADÁ \\ GRAZIBRANDT@HOTMAIL.COM \\ ELIZABETH HUBER MOREIRA \\ UNIVERSIDADE FEDERAL DE SANTA MARIA \\ SANTA MARIA, RIO GRANDE DO SUL, BRASIL \\ LIZA@UNISC.BR \\ ANALU SCHMITZ HORLLE \\ UNIVERSIDADE FEEVALE \\ NOVO HAMBURGO, RIO GRANDE DO SUL, BRASIL \\ ANALU@UNISC.BR \\ HTTP://DX.DOI.ORG/10.5902/2316882X22938
}


CONSEILS AUX VOYAGERS: REFLEXÕES SOBRE A UTILIZAÇÃO DA COMUNICAÇÃO DIGITAL NO PROCESSO DE CONSTRUÇÃO DO IMAGINÁRIO TURÍSTICO DE ESTRANGEIROS NO BRASIL

Resumo: Este artigo busca analisar, por meio de uma abordagem qualitativa, os conteúdos comunicacionais do portal institucional Voyage.gc.ca. A análise os dados analisados revelam que a violência e criminalidade urbana, assim como a figura estereotipada do malandro brasileiro são os principais objetos de informação divulgadas pelo governo canadense para turistas com destino ao Brasil.

Palavras-chave: comunicação digital; imaginário turístico; estrangeiros.

CONSEILS AUX VOYAGEURS: REFLEXIONES SOBRE EL USO DE COMUNICACIÓN DIGITAL EN EL PROCESO DE CONSTRUCCIÓN DEL IMAGINARIO TURÍSTICO DE LOS EXTRANJEROS EN BRASIL.

Resumen: En este artículo se pretende analizar, a través de un enfoque cualitativo, el contenido comunicacional de Voyage.gc.ca portal institucional. Los datos del análisis analizadas demuestran que la violencia y la delincuencia urbana, así como la figura estereotipada del tramposo de Brasil son los principales objetos de información dadas a conocer por el gobierno de Canadá para los turistas a Brasil.

Palavras-chave: comunicação digital; imaginário turístico; extranjero.

CONSEILS AUX VOYAGEURS: REFLECTIONS ON THE USE OF DIGITAL COMMUNICATION IN THE PROCESS OF CONSTRUCTION OF THE TOURIST IMAGINARY OF FOREIGNERS IN BRAZIL

Abstract: This article aims to analyze, through a qualitative approach, the content of the communication items in the institutional website Voyage. gc.ca. The data analyzed reveal that violence and urban crime, as well as the stereotypical image of the "malandro (rogue)" are the main information propagated by the Canadian government to the tourist travelling to Brazil.

Key words: digital communication; tourist imaginary; foreign. 


\section{Introdução}

A comunicação tem o potencial de interferir na escolha de um viajante ao lugar a ser visitado. Nesse sentido, a prática comunicacional no turismo, seja ela de caráter promocional ou informativa, pode inibir ou fomentar a prática turística em determinado país ou região. A comunicação digital tem contribuído para a dinamização dos roteiros turísticos. Com a intensificação dos usos da internet houve um aumento significativo da utilização da comunicação digital para divulgação de informações sobre turismo em diferentes regiões e países. No entanto, é importante perceber que o turismo se constrói a partir de uma perspectiva multisetorial e multidimensional dos diferentes agentes envolvidos no processo.

À medida que a internet democratiza os destinos turísticos para seus usuários, a partir de uma quantidade relativa de informações disponibilizadas, é importante observar que a qualidade dos conteúdos disponibilizados pelos diferentes produtores de conteúdo também são diversificadas. De acordo com Marujo (2008, p. 26) ao utilizar a internet "o consumidor de turismo está cada vez mais exposto a um fluxo maior de informações veiculadas, principalmente, pelos meios de comunicação".

Esta pesquisa busca analisar através do site voyager.ca as informações disponibilizados pelo governo canadense aos turistas com intenção de viajar ao Brasil. Nos propomos a realizar uma análise de certos elementos constitutivos do texto, com base na análise temática dos principais conteúdos veiculados sobre o Brasil pelo portal de informações do governo canadense. A partir das informações e dos conteúdos disponibilizados buscamos evidenciar o potencial da comunicação digital em (des)valorizar a brasilidade.

\section{O turismo no Brasil: um olhar sobre dados e fatos recentes}

Ao analisar o turismo no Brasil, constata-se que mesmo diante dos inúmeros problemas enfrentados, principalmente nos últimos anos, o país ainda está na rota de muitos turistas vindos de vários lugares do mundo. Prova disso são os dados apontados pelo Instituto Brasileiro de TurismoEMBRATUR (2016, http://www.embratur.gov.br/piembraturnew/open- 
cms/salalmprensa/artigos/arquivos/Turismo_potencial_de_um_novo_ presal.html), no qual consta que em 2014 o número de viagens no mundo aumentou em 4,4\%, com o deslocamento de um bilhão de turistas e giro em torno de US\$ 1,2 trilhão. Só no Brasil este dado representa 9,2\% do Produto interno Bruto produzido.

Ainda, conforme pesquisa realizada pelo ministério do turismo (2016, http://www.dadosefatos.turismo.gov.br/dadosefatos/home.html), com mais de 44 mil estrangeiros que visitaram o Brasil em 2014, constatou-se que a hospitalidade do povo brasileiro é o fator que o turista estrangeiro mais valoriza quando visita o país. Por outro lado, os preços cobrados pelos serviços turísticos são os que tem a pior avaliação.

Os entrevistados foram abordados em 15 aeroportos internacionais e em 10 fronteiras terrestres, sempre no término da visita ao país. Do total de entrevistados, 10.402 pessoas foram abordadas no período da Copa do Mundo ocorrida no Brasil em 2014.

Segundo a pesquisa, $97,2 \%$ das pessoas consideram a hospitalidade do brasileiro muito boa. A gastronomia ficou em segundo lugar com 94,4\% de aprovação. Itens como segurança pública, alojamento, transporte urbano e limpeza também foram bem avaliados, porém, questões relacionadas aos preços dos serviços turísticos, telefonia e internet e rodovias, foram os itens com menor pontuação.

Ainda segundo o levantamento realizado pelo Ministério do Turismo, os meses em que mais estrangeiros visitaram o Brasil foram junho e julho, época da Copa do Mundo, ou seja, $27 \%$ aconteceram nesse período, ultrapassado inclusive épocas consideradas de alta estação para turismo internacional, como os meses de janeiro e fevereiro, por exemplo.

A realização da copa do mundo no Brasil também explica o aumento nos gastos dos estrangeiros em 2014. Nas viagens de lazer, cada turista gastou, em média, $\mathrm{R} \$ 86,98$ por dia no Brasil, sendo que no ano anterior, esse valor foi de aproximadamente $\mathrm{R} \$ 68,55$.

De acordo com José Francisco de Salles Lopes, diretor do Departamento de Estudos e Pesquisas do Ministério do Turismo, "O turista que viaja para a Copa tem maior renda. Mais de $85 \%$ deles têm nível universitário, por exemplo. A renda familiar e pessoal é maior e, com isso, o gasto também sobe" (2016, http://www.dadosefatos.turismo.gov.br/dadosefatos/home.html).

Ainda segundo a pesquisa, cada turista estrangeiro que veio ao Brasil

Rev.Cad.Comun. Santa Maria, v.20, n.3, art 3, p.62 de 75, set/dez.2016 
em 2014 gastou, durante toda a visita, uma média de $\mathrm{R} \$ 1.165$ para viagens de lazer e de $\mathrm{R} \$ 1.618$ para as de negócios. Outro aspecto importante é que quase metade dos turistas que passaram férias no Brasil em 2014 vieram em busca de sol e praia e como segunda motivação, a Copa do Mundo.

Atrativos como natureza, entre outros, ficou em terceiro lugar com $12,8 \%$ das respostas, e as atrações culturais obtiveram $10,3 \%$ dos resultados. A avaliação geral dos estrangeiros sobre a visita ao Brasil em 2014 foi boa, pois $36 \%$ disseram que a viagem superou as expectativas, $49,1 \%$, que atendeu às expectativas, $12,6 \%$, que atendeu em parte e $2,3 \%$ se disseram decepcionados. Além disso, 95,1\% disseram ter a intenção de retornar ao Brasil.

Em 2015, confrome dados da EMBRATUR (http://www.embratur.gov. br/piembraturnew/opencms/salalmprensa/noticias/arquivos/Brasil_recebeu_mais_de_6_milhoes_de_estrangeiros_em_2015.html) o número de turistas se manteve praticamente igual aos dados de 2014, ficando apenas em 1,9\% menor, dado considerado bom, tendo em vista o evento de proporção mundial sediado em 2014. Porém, se comparado com o ano de 2013, o Brasil apresentou um crescimento de $8,5 \%$ em relação ao número de visitantes estrangeiros.

No ano de 2016, no que diz respeito ao turismo internacional, a exemplo da copa do mundo realizada em 2014 e que causou boa impressão para os turistas, têm-se as Olimpíadas que serão realizadas no mês de agosto, no Rio de Janeiro, local preferido dos turistas estrangeiros devido a suas belas praias e demais cartões postais.

Conforme dados da Embratur, a rede hoteleira já registra a ocupação de $90 \%$ dos quartos para os jogos olímpicos. Em abril de 2016, o Rio Convention \& Visitors Bureau ${ }^{2}$ (2016, http://www.rcvb.com.br/quem-somos/) em parceria com a ForwardKeys ${ }^{3}$ divulgou um levantamento no qual destacou que as reservas de hotéis para o período dos jogos olímpicos devem ficar 208\% superior no período do mundial de 2014. Diante deste contexto, pode-se destacar que, além dos jogos olímpicos, datas como reveillon e carnaval são períodos propícios para o turismo no Brasil, tendo em vista todos os atrativos oferecidos pelos brasileiros, em especial nestas datas.

Prova disto é a reportagem do jornal norte-americano La Visión News-

2 Instituição de turismo do Rio de Janeiro.

3 Centro de pesquisa com foco em Big data e negócios inteligentes.

Rev.Cad.Comun. Santa Maria, v.20, n.3, art 3, p.63 de 75, set/dez.2016 
paper (2016,http://www.embratur.gov.br/piembraturnew/opencms/salalmprensa/noticias/arquivos/Sao_Paulo_ganha_destaque_em_publicacao_internacional_html), divulgada em março de 2016, na qual diz que "Conhecer outros países amplia a mente e a alma. Se somarmos a isso divertimento, riqueza cultural e delícias gastronômicas, o Brasil, então, além de ser um destino turístico, é o local ideal para visitar em sua próxima viagem. O Brasil é alegria, futebol, carnaval, Jogos Olímpicos e muito mais".

Por outro lado, conforme matéria divulgada em março de 2016 pelo portal Radio France Internationale (2016, http://br.rfi.fr/brasil/20160326-zika-e-violencia-afastam-turistas-norte-americanos-do-brasil-o), na qual diz que o Zika vírus e os altos índices de violência têm afastado os turistas americanos do Brasil. A publicação diz que em uma pesquisa aplicada pelo IPEA 4 , o Brasil ocupa a primeira posição em crimes no planeta. Além disso, os altos índices de afetados pelo Virus Zika também contribui para o desinteresse do turista americano.

Com base nestas constatações, é necessário que o turismo no Brasil seja avaliado e planejado de forma que possa competir por igual com outros países que não possuem a dimensão da matéria prima que possui o Brasil, mas por questão de gestão e profissionalismo estão no patamar dos países mais requisitados turisticamente.

Nesta perspectiva, cabe citar Da Matta(1997) quando afirma que:

No Brasil temos carnavais e hierarquias, igualdades e aristocracias, com a cordialidade do encontro cheio de sorrisos cedendo lugar, no momento seguinte, à terrível violência dos antipáticos "sabe com quem está falando?" E também temos samba, cachaça, praia e futebol, mas de permeio com "democracia relativa" e "capitalismo a brasileira", um sistema onde só trabalhadores correm riscos, embora, como se sabe, não tenham lucro algum. (DA MATTA, 1997, p.16).

Diante desta afirmação, na qual o "jeitinho brasileiro" apresentado por Da Matta (1997) encanta e seduz e, tendo em vista o desenvolvimento sócio econômico do Brasil nos últimos tempos no que tange os investimentos na área do turismo, o país está se tornando, mesmo que ainda de forma tímida, um mercado turístico competitivo e bastante atrativo. 


\section{A comunicação digital no turismo}

As redes sociais digitais tornam-se hoje uma das principais aliadas do turismo, com objetivo de divulgar roteiros e atrair pessoas do mundo inteiro. A inserção das redes sociais digitais associadas ao turismo tem por objetivo valorizar as belezas naturais da viagem que se pretende fazer, aproximando as pessoas que estão em busca de um destino para passar suas férias, compartilhando informações dos lugares visitados, além de reforçar a inovação no setor de turismo que, por consequência, acaba fortalecendo a reputação das agências nacionais de turismo, responsáveis em divulgar a imagem do seu país.

A comunicação digital torna-se determinante para influenciar o consumidor, uma vez que a aquisição do pacote turístico ocorre antes do contato direto com o destino desejado. Desta forma, a internet atua como canal de distribuição de informações que permite maior interação com o usuário, o que normalmente não é possível com o meio de comunicação tradicional, como revista, televisão, jornal, entre outros. Tal distinção tem provocado mudanças consideráveis no setor do turismo, fazendo surgir um consumidor cada vez mais autônomo, exigente e seguro, em razão do conjunto de informações ao qual está exposto.

Portanto, a comunicação digital contribui tanto positivamente quanto negativamente na promoção do turismo, pois caso se decepcione, o turista utiliza as redes sociais digitais para manifestar sua insatisfação, o que contribui significativamente na prospecção de melhorias do setor.

No Brasil, a rede social digital é uma das principais formas de divulgar e fomentar o setor. A internet tem sido um apoio fundamental em campanhas de marketing do turismo como, por exemplo, a campanha \#PartiuBrasil, do Ministério do Turismo, que tem por objetivo estimular os brasileiros a viajar pelo país e incentivar os agentes de viagem a privilegiar os destinos nacionais. Além disso, pode-se citar o caso da cidade de Maceió, no qual a Secretaria de Turismo conseguiu em menos de cinco meses divulgar a campanha \#ExperimenteMaceió por meio das redes sociais digitais Facebook, Instagram e Snapchat. Como resultado, Maceió conseguiu mais de um milhão de seguidores que passaram a acompanhar as novida-

Rev.Cad.Comun. Santa Maria, v.20, n.3, art 3, p.65 de 75, set/dez.2016 
des turísticas do local além de ter 14 mil compartilhamentos.

Em relação ao turismo internacional, e com base nos dados do Ministério do Turismo (2016, http://www.turismo.gov.br/\%C3\%BAltimas-not\%C3\%ADcias/5545-o-turismo-turbinado-pelas-redes-sociais.html), estima-se que $68 \%$ dos estrangeiros que visitaram o Brasil no ano de 2014, utilizaram a internet para planejar a viagem. Além disso, a cada hora, internautas de todo o mundo realizam 625 mil buscas no site Google sobre viagens. Ainda conforme publicação do Ministério do Turismo, o Brasil é destaque nas principais redes sociais que envolvem turistas pela internet, seja pela beleza de suas praias, pela gastronomia, entre outros atrativos.

O Ministério do Turismo brasileiro está presente em várias redes sociais digitais, tais como Facebook, Twitter, Instagram, Youtube, Google +, Pinterest e Flickr. De acordo com o site Iconosquare (2016, http://iconosquare.com/), responsável em medir estatísticas de perfis e publicações no Instagram, a página brasileira conseguiu atingir 41 mil seguidores em um período de três anos, além de receber mais de 179 mil fotos e mais de 1 milhão de curtidas nas fotos publicadas.

Conforme dados da ABEOC Brasil - Associação Brasileira de Empresas de Eventos (2016, http://www.abeoc.org.br/2015/04/redes-sociais-ampliam-a-comunicacao-do-turismo/), no ano de 2015 mais de 318 mil seguidores curtiram a página do Ministério do Turismo brasileiro, 170 mil no Twitter e mais 19 mil curtidas no Instagram. Ainda conforme a publicação, o Ministério do Turismo se comunica com o público por meio de um blog e foi um dos primeiros órgãos governamentais a usar o Pinterest.

Diante deste contexto, as redes sociais digitais, hoje, devem ser consideradas pelas agências de viagens como fortes aliadas, sendo que as mesmas tiveram que se adaptar ao sistema da comunicação digital tendo em vista que a difusão dos destinos de viagem pela informação eletrônica acabou por criar um novo perfil de turista, que busca cada vez mais informações antes de escolher seu destino final.

Desta forma, pode-se concluir que as redes sociais digitais nos dias atuais têm o poder de promover e também de desqualificar o turismo de determinado local, o que atribui ao país maior responsabilidade no que tange a sua promoção e demais estratégias para receber e agradar o turista. Percebe-se que as exigências em relação ao país de destino têm aumentado consideravelmente nos últimos tempos, sendo que grande responsabilidade pode ser creditada a comunicação digital.

Rev.Cad.Comun. Santa Maria, v.20, n.3, art 3, p.66 de 75, set/dez.2016 


\section{O Brasil visto de fora: análise das informações do portal institucional do Governo Canadense Voyage.gc.ca}

O site Voyage.gc.ca é mantido pelo governo canadense e busca dar informações sobre viagem e turismo aos viajantes canadenses. As informações no site estão divididas em sessões temáticas, sendo estas: conseIhos aos viajantes e avisos; atrações turísticas, eventos e experiências no Canadá; viagem para o exterior; viagem de avião e retorno ao Canadá; assistência em países estrangeiros; mantenha-se conectado e viagens (outros).

Através desse link o governo fornece aos cidadãos canadenses informações oficiais do governo do Canadá relativas a situações que podem comprometer a segurança e o bem-estar de turistas e viajantes canadenses em países estrangeiros. Dentre as informações dispostas no site, nos interessa particularmente as sessões temáticas Conseils aux voyageurs et avertissements (conselho aos viajantes e avisos) e voyager à l'étranger (viagem para o exterior). Nestas duas seções encontramos informações úteis sobre saúde e segurança, os documentos de viagem necessários, bem como os tempos de espera na fronteira, entre outros.

Seja qual for o destino de viajantes e turistas canadenses, há uma recomendação do governo canadense de verificar as informações e os conselhos da página durante dois momentos: ao planejar a viagem e antes de deixar o Canadá. Se um aviso for emitido para alguma região ou país de destino, é importante aos canadenses de se certificarem de que forma essas informações podem afetar o seguro saúde ou o seguro de cancelamento de viagem.

Ao consultar a seção conselho aos viajantes e avisos há uma mensagem em caixa alta que diz o seguinte: "Vous êtes le seul responsable de votre sécurité". Podemos traduzir a frase da seguinte forma: Você é o único responsável pela sua segurança. Logo abaixo é possível selecionar um país e verificar as informações apresentadas. Ao selecionarmos o Brasil como destinação abrem novas seções temáticas, como: avisos, segurança, exigências de entrada e saída, saúde, leis e costumes, catástrofes naturais e clima, além do item assistência.

Ao explorarmos as informações apresentadas no item avisos nos deRev.Cad.Comun. Santa Maria, v.20, n.3, art 3, p.67 de 75, set/dez.2016 
paramos com as seguintes informações apresentadas abaixo:

\section{BRASIL - Tenha muito cuidade}

Nenhum aviso está em vigor para todo o Brasil. No entanto, deve-se ter um grande cuidado por causa da alta taxa de criminalidade e incidentes violentos atribuíveis, entre outros, a grupos organizados em áreas urbanas.

Conselhos de saúde para os viajantes - infecção pelo vírus Zika

A Agência de Saúde Pública do Canadá emitiu conselhos de saúde para os viajantes para a infecção pelo vírus Zika: situação global que recomenda a canadenses tomar precauções especiais para a saúde quando se viaja em países atualmente afetados. Mulheres grávidas e mulheres que planejam engravidar devem evitar todas as viagens ao país onde há surtos de vírus Zika. Veja Saúde para mais informações.

O medo de contrair dengue ou zika vírus tem preocupado turistas estrangeiros com destino ao Brasil. Nesse sentido o turismo se confronta atualmente com os impactos econômicos negativos que a dengue e o zika vírus apresentam. O governo brasileiro, na última década, se preocupou muito com ações governamentais de infraestrutura para desenvolver o turismo no país, especialmente porque sediou em 2013 a Copa do Mundo e nesse ano será sede dos Jogos Olímpicos. No entanto, é importante evidenciar que campanhas preventivas na área da saúde pública ambiental também são necessárias para fomentar o turismo no Brasil. A infecção pelo zika vírus ganhou visibilidade mundial e não foi diferente para com os turistas canadenses. Por meio do seu portal institucional o governo canadense solicita que mulheres grávidas ou que pretendem engravidar evitem viajar ao Brasil. A perda de divisas em função da suspensão do fluxo turístico rumo ao Brasil já é uma realidade. De acordo com o Banco Mundial, o impacto do zika vírus pode gerar perda de $U \$ \$ 3,478$ bilhões ao PIB local em 2016 em países da América Latina e do Caribe. (2016, https:// latinaspaginas.wordpress.com/2016/02/18/zika-pode-impor-perda-de-us-35-bi-ao-pib-da-america-latina-e-caribe-em-2016/).

Em relação a segurança, o governo canadense adverte para os cidadãos do seu país uma especial atenção a criminalidade urbana associada aos grupos organizados. Ao buscarmos informações na seção segurança, esta se subdivide em diferentes blocos temáticos de informações, com destaque para criminalidade, favelas e violência ligada a grupos organizados, segurança de mulheres, manifestações e agitação civil, fronteiras

Rev.Cad.Comun. Santa Maria, v.20, n.3, art 3, p.68 de 75, set/dez.2016 
com a Colômbia e Venezuela, informações gerais no que tange a segurança. No item criminalidade as seguintes informações são apresentadas:

\begin{abstract}
A criminalidade é um problema sério em todo o Brasil. Tanto pequenos delitos como crimes violentos, incluindo homicídio, são mais comuns em centros urbanos, especialmente no Rio de Janeiro (ou Rio), São Paulo, Brasília, Recife e Salvador, particularmente em áreas adjacentes aos bairros desfavorecidos (veja abaixo a seção sobre as favelas). Os crimes sofridos pelos turistas estrangeiros são principalmente roubo, mas às vezes ocorrem agressões, porque há uma grande quantidade de armas em circulação e os criminosos não hesitam em recorrer à violência. (2016, https://voyage.gc.ca/destinations/bresil).
\end{abstract}

Casos de violência e criminalidade podem igualmente afetar a escoIha dos destinos turísticos. A segurança é um fator importante ao optar pelo local a ser visitado. Para Catai e Rejowski (2005, p. 249) “as variantes geográficas, a gravidade dos atos, o poder de penetração na mídia são questões a serem consideradas em abordagens sobre o tema". O governo canadense destina especial atenção para a criminalidade presente em determinadas metrópoles brasileiras e enfatiza, sobretudo, especial atenção dos turistas com os bairros desfavorecidos nessas metrópoles.

A imagem das principais metrópoles brasileiras, especialmente da cidade do Rio de Janeiro, é retratada pelas suas belezas naturais pelas agências de viagem. Já pelos portais institucionais governamentais e que dão conselhos aos viajantes a ênfase principal fica atrelada às diferentes formas de criminalidade urbana. A criminalidade é percebida como uma questão central nas orientações a turistas canadenses com destino ao Brasil. Ao mesmo tempo, roteiros turísticos em áreas desfavorecidas como o favela tour se popularizam entre os estrangeiros.

Ou seja, se a violência repulsa turistas, o turismo da miséria atrai visitantes nas grandes favelas brasileiras. O que será que move esses turistas em direção às favelas? Seria a curiosidade ou a solidariedade? A transformação da pobreza em atração não é recente. A elite inglesa, durante o período vitoriano, costumava visitar bairros desfavorecidos na Europa como forma de identificar as segregações que existiam nas cidades europeias. Esse fenômeno era chamado de slumming (FREIRE-MEDEIROS, 2009). A autora evidencia que no caso do turismo de favela, geralmente os turistas buscam se confrontar com realidades sociais as quais desconhecem.

Rev.Cad.Comun. Santa Maria, v.20, n.3, art 3, p.69 de 75, set/dez.2016 
A violência e a realidade das favelas brasileiras também passa a ser retratada no cenário internacional a partir de produções cinematográficas, onde são exibidas imagens realistas, mas também estilizadas das favelas, como é o caso do filme Cidade de Deus (FREIRE-MEDEIROS, 2009). A geografia imaginária da favela não oculta a violência presente nesses espaços. Nesse sentido, para facilitar os locais de visitação de turistas a cartografia turística e a geotecnologia se apresentam como ferramentas úteis a serem utilizadas por turistas e possibilitam um reconhecimento físico-territorial dos locais a serem visitados. De certa forma, o sentimento de insegurança do turista pode ser minimizado com esse reconhecimento.

Contudo, o portal voyager.gc.ca reforça que a vigilância do turista canadense deve ser redobrada no Brasil, fato este presente no trecho abaixo:

Preste atenção quando recém conhecidos pedirem informações ou ofereçam amizade, hospitalidade ou assistência. Um dos truques mais comuns de criminosos é de se apresentar como bons samaritanos oferecendo sua ajuda aos turistas que parecem estar fora do lugar. Se você se perder, entre em um comércio ou um hotel para pedir ajuda. Se alguém derramar algo em você, não permita que essa pessoa se aproxime para ajudá-la, pois pode ser uma manobra para roubar sua carteira. (2016, https://voyage.gc.ca/destinations/bresil, tradução nossa).

A relação social que poderia existir entre os moradores e os turistas provavelmente já se constrói fragilizada no imaginário do estrangeiro canadense que terá o Brasil como destino. No caso do portal voyager.gc.ca há uma utilização um tanto quanto tecnicista dos meios digitais de comunicação para esses turistas. Wolton (2010, p. 29) alerta que a midiatização na transmissão de informações tecnologizadas não promove a humanização e socialização do processo de comunicação.

Para Lima (1999) uma das razões principais do turismo tem relação com o interesse do viajante em conviver com pessoas nativas, conhecer novas culturas e vivenciar novas experiências. Nessa perspectiva, a atividade turística tem um aspecto social importante, a medida que promove a interação entre indivíduos e a expansão das trocas culturais. A divulgação de informações como as acima divulgadas pelo portal institucional canadense podem reforçar preconceitos e fomentar estereótipos, promovendo uma desvalorização da cultura e identidade, além de fomentar a crista- 
brasileiro malandro e sem escrúpulos é retratada nas informações divulgadas. O personagem de animação Zé Carioca, criado pela Disney durante a década de 1940, ainda representa a imagem do brasileiro no exterior, marcado por uma espécie de culto ao malandro. $O$ viés da malandragem então parece circundar o país de grandes dimensões territoriais e da pluralidade cultural. O conteúdo abordado pelo portal institucional canadense acaba contribuindo, em suas proporções depreciativas, para o fortalecimento deste rótulo indesejável em relação ao brasileiro.

Sobre a segurança das mulheres o portal apresenta as seguintes informações que estão listadas abaixo:

\begin{abstract}
Mulheres viajando sozinhas devem ter cautela ao lidar com estranhos ou novos conhecidos, e é particularmente indicado estarem atentas a convites. Evite viajar sozinha à noite e, na medida do possível, não use bolsa. Nunca deixe sua bebida desacompanhada e não aceite bebidas de um estranho. (2016, https://voyage.gc.ca/destinations/bresil, tradução nossa).
\end{abstract}

Ao buscar uma compreensão do conteúdo mencionado pelo portal institucional percebe-se uma nítida contextualização de representações sociais em termos de gênero, especialmente atrelada as questões que envolvem a feminilidade e a sexualidade. O turismo internacional feminino, especialmente a partir do portal analisado, enfoca as estruturas de gênero desiguais presentes no nosso país, especialmente ligada a questão da possível "fragilidade" da mulher estrangeira perante os nativos. Diante do exposto, a relação entre turismo, violência e sexualidade tem ganhado importância em reportagens de jornais e revistas especializadas, evidenciando, sobretudo, os casos de violência em relação a turistas no país.

Historicamente a desigualdade de gênero é um fator preponderante na configuração da sociedade brasileira. No entanto, a mulher brasileira vem aos poucos conquistando direitos sociais e jurídicos. Os movimentos sociais de mulheres se tornam mais frequentes no país. Em relação as turistas estrangeiras, as informações do portal privilegiam um olhar com enfoque de acontecimentos noticiados pela mídia. O mesmo ocorre no que diz respeito as manifestações civis

Greves dos trabalhadores e natureza política ocorrem regularmente em várias cidades brasileiras [...]. Regularmente acontecem manifestações nacionais para protestar contra a corrupção

Rev.Cad.Comun. Santa Maria, v.20, n.3, art 3, p.71 de 75, set/dez.2016 


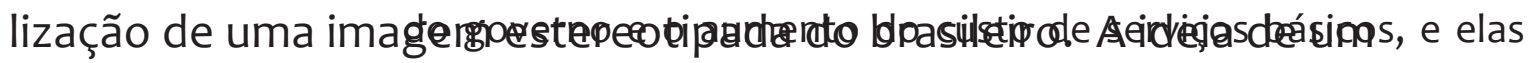
tendem a aumentar em número e intensidade durante grandes eventos que atraem visitantes estrangeiros.

Percebe-se, claramente, no site analisado, que os principais temas abordados em forma de alertas aos turistas canadenses com intenção de visitar o Brasil dizem respeito à violência urbana e à saúde pública. São mensagens contundentes sobre os problemas enfrentados pelo Brasil especialmente nestes dois aspectos.

\section{Considerações}

Ao analisarmos a relação do turismo Norte/Sul, especialmente a partir da perspectiva dos conteúdos e informações disponibilizados no portal voyager.ca para turistas canadenses com intenção de viajar ao Brasil percebemos que este vem se desenvolvendo a partir da noção de insegurança constituída, por alguns momentos justificada e por outros não. Cabe salientar que essa noção de "insegurança” pode contribuir para desvalorizar a brasilidade que tanto se busca realçar na promoção de roteiros turísticos no Brasil. Contudo, é importante perceber que a construção do imaginário turístico de estrangeiros no Brasil é vasta e corresponde a vários universos ligados, sendo estes atrelados sobretudo a experiência turística individual (lazer, aventura, férias, peregrinação, errância, descoberta, entre outros). É interessante perceber que a comunicação digital utilizada por sites institucionais como o voyager.ca são igualmente reflexos da cultura e tendem a uniformização dos estilos de vida ou ainda dos estilos de se viajar, ancorados, muitas vezes, em estereótipos e clichês construídos sobre o país a ser visitado, baseados na perspectiva de um saber standard desse local. 


\section{REFERÊNCIAS}

ABEOC Brasil - Associação Brasileira de Empresas de Eventos. Disponível me < http:// www.abeoc.org.br/2015/04/redes-sociais-ampliam-a-comunicacao-do-turismo/> Acesso em 24.maio.2016

DA MATTA, Roberto. Carnavais, malandros e heróis: para uma sociologia do dilema brasileiro. 6. ed. Rio de Janeiro, Ed. Rocco, 1997.

EMBRATUR. Apresenta informações sobre o turismo brasileiro. Disponível em < http://www.embratur.gov.br/ > Acesso em: 13 maio 2016.

FORWARDKEYS. Apresenta informações sobre turismo e negócios. Disponível em: https://translate.google.com.br/transläte?hl=pt-BR\&sl=en\&u=http://forwardkeys.com/revenue-management/article/forwarddata.html\&prev=search > Acesso em 13 maio 2016.

FREIRE-MEDEIROS, Bianca. Gringo na laje: produção, circulação e consumo da favela turística. Rio de Janeiro: Editora FGV, 2009.

GLOBO. Disponível em: http://g1.globo.com/economia/noticia/2015/11/hospitalidade-do-brasil-e-item-mais-bem-avaliado-por-turistas-em-pesquisa1.html >. Acesso em: 13 maio 2016.

GOUVERNEMENT DU CANADA. Apresenta informações sobre o Brasil. Disponível em https://voyage.gc.ca/destinations/bresil. Acesso em 15 de abril de 2016.

ICONOSQUARE. Apresenta informações sobre a ferramenta Iconosquare. Disponível em < http://iconosquare.com/> Acesso em: 24.maio.2016

LA VISION NEWSPAPER. http://www.embratur.gov.br/piembratur-new/opencms/salalmprensa/noticias/arquivos/Sao_Paulo_ganha_destaque_em_publicacao_internacional_.html)

LIMA, Luiz Cruz. O planejamento regional ajuda o turismo? In: YÁZIGI, Eduardo; CARLOS, Ana Fani Alessandri; CRUZ, Ritá de Cássia Ariza da (Orgs). Turismo: espaço, paisagem e cultura. 2. ed. São Paulo: Hucitec, 1999.

MINISTÉRIO DO TURISMO. Apresenta informações sobre o turismo brasileiro. Disponível em < http://www.turismo.gov.br/ > Acesso em 13. Mai. 2016.

. Apresenta informações sobre o turismo brasileiro. Disponível em < http:// WWW.turismo.gov.br/ > Acesso em 24. Mai. 2016.

RADIO FRANCE INTERNATIONALE . Apresenta informações sobre Zika e violência afastam turistas norte-americanos do Brasil. Disponível'em: <http://br.rfi.fr/brasil/ 20160326-zika-e-violencia-afastam-turistas-norte-americanos-do-brasil-o >. Acesso em: 13 maio 2016.

RIO CONVENTIO \& VISITORS BUREAU. Apresenta informações sobre turismo. Disponível em http://www.rcvb.com.br/quem-somos/. Acesso em: 20 de junho de 2016. 
PÁGINAS LATINAS. Apresenta informações sobre sociedade, política e cultura latino-americana . Disponível em: https://latinaspaginas.wordpress.com/2016/02/18/zika-pode-impor-perda-de-us-35-bi-ao-pib-da-america-latina-e-caribe-em-2016/). Acesso em: 20 de junho de 2016.

CATAI, Henrique; REJOWSKI, Mirian. Criminalidade e turismo em São Paulo, Brasil: a violência registrada junto aos turistas estrangeiros . Revista Turismo em Análise, v. 16, n. 2, p. 223-243, novembro 2005.

WOLTON, Dominique. Informar não é comunicar. Porto Alegre: Sulina, 2010.

MARUJO, M. Turismo e comunicação. Castelo Branco: RVJ Editores, 2008. 


\section{Resumo sobre autores:}

\section{Grazielle Betina Brandt}

Doutora em Desenvolvimento Regional pela Université du Quebéc à Rimouski (Canadá). É professora do e pesquisadora do Departamento de Comunicação Social e do Programa de Pós-Graduação em Desenvolvimento Regional da Universidade de Santa Cruz do Sul.

Elizabeth Huber Moreira

Professora do Departamento de Comunicação Social da Universidade de Santa Cruz do Sul e Doutoranda em Comunicação Midiática na Universidade Federal de Santa Maria.

Analu Schmitz Horlle

Mestre em Diversidade Cultural e Inclusão Social pela Universidade Feevale (2015). É docente no curso de Comunicação Social da Universidade de Santa Cruz do Sul, ministrando disciplinas no curso de Relações Públicas.

RECEBIDO EM: 30/06/2016

ACEITO EM: 23/08/2016 